PAPER

\title{
Risk awareness and knowledge of patients with stroke: results of a questionnaire survey 3 months after stroke
}

\author{
A Croquelois, J Bogousslavsky
}

See end of article for authors' affiliations ....................

Correspondence to: Dr Alexandre Croquelois, Neurology Department, Centre Hospitalier Universitaire Vaudois (CHUV), Rue du Bugnon 46, 1011 Lausanne, Switzerland; alexandre. croquelois@chuv.ch

Received 18 August 2005 Revised version received 26 February 2006 Accepted

27 February 2006 Published Online First 20 March 2006
Background: Secondary prevention of stroke has been shown to dramatically reduce recurrence and has been described as suboptimal.

Objective: To analyse patients' awareness and knowledge about cerebrovascular risk factors (CVRF) and their influence on CVRF control.

Methods: Patients $(n=164)$ who were attending a stroke outpatient clinic for the first time after hospital discharge (3 months) for a first stroke were asked to answer a short questionnaire including questions on awareness and knowledge of CVRF, visits to a CVRF specialist, number of visits to a general practitioner, adherence to drug treatments, cigarette smoking and cessation.

Results: CVRF were spontaneously mentioned as relevant for their stroke by only $13 \%$ of patients. A specialist was visited by only one-third of the patients and a general practitioner was not visited at all by $27 \%$ of the patients since their stroke. Awareness was inversely correlated with older age and good recovery. More than half of the patients had high blood pressure $(\geqslant 140 \mathrm{mmHg}$ for systolic and $\geqslant 90$ $\mathrm{mmHg}$ for diastolic values) at the time of follow-up. These high values were correlated with poor awareness. Appropriate secondary stroke prevention measures were not received by one-fourth of the patients; this was also correlated with poor awareness.

Conclusions: CVRF control is not optimal and is at least partially related to patients' awareness and knowledge and suboptimal medical follow-up. Older patients and patients with excellent recovery are at particular risk for poor awareness and CVRF control.
S troke is the third leading cause of death, the second cause of dementia and the first leading cause of physical disability in adults in Western countries. ${ }^{1}$ Despite recent advances in acute treatment, these newer treatments are delivered in fewer than $5 \%$ of cases. ${ }^{2}$ Thus, neuro-rehabilitation and secondary prevention of stroke remain the mainstay in the management of stroke. Patients with stroke have 15 times higher risk of recurrence of stroke than the general population $^{3}$ and this risk is further increased in the presence of cerebrovascular risk factors (CVRF). ${ }^{4-6}$ According to the European Stroke Initiative, ${ }^{7}$ these risk factors include systemic arterial hypertension, myocardial infarction, atrial fibrillation, diabetes mellitus, high cholesterol levels, carotid artery disease, smoking and alcohol use, some of them depending on patients' habits. ${ }^{8}$ A lot of evidence exists for a decrease in recurrence of stroke after receiving treatment for CVRF. ${ }^{10}$ Secondary stroke prevention, remains suboptimal. For instance, Girot et $a l^{11}$ reported that according to the European guidelines for stroke management, $78 \%$ of patients who had a stroke in the past 6 years did not receive appropriate secondary prevention measures. ${ }^{11}$ We hypothesise that patients' awareness and knowledge could have a role in suboptimal post-stroke management. The aim of this work is therefore to evaluate patients' awareness and knowledge and the factors that could influence them (age, sex, location of, origin and severity of stroke). The determinants of suboptimal secondary prevention will also be established by persistent high blood pressure 3 months after stroke.

\section{METHODS}

We studied 286 consecutive patients who were attending our stroke outpatient clinic for the first time 3 months after being discharged from hospital for a first stroke between January and December 2004. At the time of stroke, patients received appropriate information regarding their CVRF as well as secondary stroke prevention before discharge. Patients who could not or refused to attend the follow-up visit $(\mathrm{n}=74)$ and those who were unable to answer the questionnaire $(n=48)$ were excluded. The patients who were unable to answer the questionnaire were those with dementia $(n=30)$ and those presenting with severe aphasia $(n=18)$. The remaining 164 patients were included in the study. Personal data recorded were age, sex, location and aetiology of stroke, CVRF, National Institute of Health Stroke Scale (NIHSS) at admission, modified Rankin Scale (mRS) at discharge, NIHSS and mRS at 3 months and current treatment. The first question of the questionnaire answered by the patients was open-ended, to evaluate spontaneous answers. Questions 2 ("Do you think that hypertension, cigarette smoking, diabetes and/or hypercholesterolaemia could have been involved in your stroke?") and 3 ("Have you been informed that hypertension, cigarette smoking, diabetes and/or hypercholesterolaemia are involved in stroke?") assessed patients' knowledge and awareness. The number of visits to a specialist since stroke and those to a general practitioner were then assessed. The last three questions explored adherence to drug treatment, smoking habits and possible smoking cessation.

Scores on awareness and knowledge were developed as follows: patients received one point for each of their unmentioned CVRF in answers to questions 2 and 3. So, a patient who did not mention two of three CVRF in answer to

Abbreviations: CVRF, cerebrovascular risk factors; mRS, modified Rankin Scale; NIHSS, National Institute of Health Stroke Scale 
question 2 had an awareness score of 2 . Influence of age, sex, location and origin of stroke, NIHSS and mRS on both scores was then assessed.

Blood pressures were measured three times to the nearest $5 \mathrm{~mm} \mathrm{Hg}$ after interview, with the patient in the supine position. The mean of the three obtained values was then calculated and recorded. High blood pressure was defined as $\geqslant 140 \mathrm{~mm} \mathrm{Hg}$ for systolic and $\geqslant 90 \mathrm{~mm} \mathrm{Hg}$ for diastolic values. The influence of age, sex, location and origin of stroke, NIHSS, mRS, high blood pressure at admission, and awareness and knowledge scores on high blood pressure at 3 months was then evaluated.

\section{Statistical analysis}

Statistical analysis was carried out using the SAS package (V.9.1, 2003). For continuous variables (NIHSS, mRS), data were checked for normal distribution. Relation between two continuous variables were investigated using linear regression. Comparisons of means in two groups (eg, male and female) were made using the unpaired Student's t test. For comparisons that required the use of the means of more than two groups (eg, origins and locations of stroke), we used an analysis of variance. The $\chi^{2}$ test was used for frequency comparisons. Analysis of the relation between various factors and the awareness and knowledge scores and high blood pressure at 3 months was performed using multilinear regression modelling.

\section{RESULTS}

Of the 164 patients included in the study, 95 (57.9\%) were men and $69(42.1 \%)$ were women. Mean age was 66 (range, 19-97) years. At the time of stroke, $66.5 \%$ of the patients had a history of hypertension, $24.4 \%$ of cigarette smoking, $16.5 \%$ of diabetes and $61.6 \%$ of hypercholesterolaemia. With respect to the aforementioned limits, $95(57.9 \%)$ patients had at least one of the two values above the limits. Among the patients with a history of hypertension at the time of stroke, 74 $(67.9 \%)$ of 109 still had elevated values.

In answer to question $1,65.2 \%$ of patients admitted that they did not know the origin of their stroke, and $13.4 \%$ spontaneously mentioned one or more CVRF. Of the 109 patients known to have high blood pressure at the time of stroke, 51 (46.8\%) recognised high blood pressure as CVRF, Results for cigarette smokers and smoking, patients with diabetes and diabetes and patients with a high level of cholesterol and hypercholesterolaemia were $75.0 \%, 48.1 \%$ and $40.6 \%$, respectively. Of the 164 included patients, 94 $(57 \%)$ did not recognise at least one CVRF. Of the 109 patients with known high blood pressure at the time of stroke, $64(58.7 \%)$ recollect having been informed that high blood pressure is one of the CVRF. Results for cigarette smokers and smoking, patients with diabetes and diabetes and patients with a high level of cholesterol and hypercholesterolaemia were $75.0 \%, 40.7 \%$ and $57.4 \%$, respectively. Of the 164 included patients, 73 (45\%) did not recognise at least one CVRF. This result was significantly different from the result for question 2 ( $57 \% v 45 \%, \chi^{2}$ test, $\left.\mathrm{p}<0.05\right)$.

In all, 38 (34.9\%) patients visited a cardiologist, 11 (27.5\%) of the 40 cigarette smokers attended a smoking cessation programme and $7(25.9 \%)$ of the 27 patients with diabetes visited a diabetologist following their stroke. The mean number of general practitioner visits per month was 0.62 (range, 0-4.21); 44 (26.8\%) patients had not visited their general practitioner since their stroke. According to the patients, drug adherence was excellent. Altogether, $2.8 \%$ of patients with high blood pressure, none of the patients with diabetes, $8.9 \%$ of patients with hypercholesterolaemia and $5.6 \%$ of patients having antiaggregant or anticoagulant therapy admitted that they had forgotten to take their treatment at least once a month. Of the 40 smokers, 17 $(42.5 \%)$ had quit since their stroke.

By using the logistic regression model with all the factors described above, we found that the awareness score was significantly higher for patients who were older $(p<0.01)$ and patients with lower NIHSS at 3 months $(p<0.05)$, whereas the knowledge score was significantly higher only for patients who were older $(\mathrm{p}<0.01)$.

With the use of the same model, persistent high blood pressure at 3 months was found to be significantly more frequent in patients with a higher awareness score $(\mathrm{p}<0.05)$.

At 3 months, 41 (25\%) patients did not receive at least one of the required secondary prevention treatments. Interestingly, these patients had an awareness score significantly higher than those who received full appropriate secondary prevention treatment(mean score $1.15 \vee 0.77, \mathrm{t}$ test, $\mathrm{p}<0.05$ ).

\section{DISCUSSION}

CVRF control remains a major objective in stroke follow-up. In our study, awareness was relatively poor in patients with stroke, with $<50 \%$ of CVRF being recognised as relevant. Kothari et $a l^{12}$ described that $43 \%$ of patients did not know a single risk factor for stroke at the time of the cerebrovascular event. In the same way, in a study assessing knowledge and awareness about stroke in a representative sample of women, Ferris et $a l^{13}$ also reported poor results, especially among people who are at highest risk.

We previously described that patients' beliefs could vary and diverge from doctors' opinions, with most of them being non-medical or non-congruent medical explanations. ${ }^{14}$ To a certain degree, we observed this again in this study, with some patients being informed that CVRF could cause stroke, but still not admitting the role of CVRF in their experience of stroke. Medical follow-up was also non-optimal, with only one-third of patients visiting a specialist for their CVRF and $27 \%$ not visiting their general practitioner since their stroke.

Awareness was independently negatively influenced by older age and excellent recovery. Interestingly, patients who showed excellent recovery also visited their general practitioner less often.

Finally, blood pressure control was suboptimal at 3 months and high blood pressure was more frequent in patients with poor awareness.

This study was a single-centre study with known limitations, which did not explore all the CVRF. A multicentre study would therefore form the next step in confirming our results and comparing them with the results of the other CVRF. Another bias could have been induced by patients refusing to attend at 3 months after discharge from hospital mainly because of poor awareness.

In conclusion, we have shown that despite an improvement in treatment, CVRF control is not optimal and may be related to the patients' awareness and knowledge and suboptimal medical follow-up. Older patients and patients with excellent recovery are at particular risk for poor awareness and CVRF control.

\section{ACKNOWLEDGEMENTS}

We thank Dr En-Ling Leung Ki and Sebastian Dieguez for reviewing the manuscript and Dr Rudolf Kraftsik for help in statistical analysis.

\section{Authors' affiliations}

A Croquelois, J Bogousslavsky, Department of Neurology, Centre Hospitalier Universitaire Vaudois (CHUV), Switzerland

Competing interests: None declared. 


\section{REFERENCES}

1 Murray CJ, Lopez AD. Global mortality, disability, and the contribution of risk factors: global burden of disease study. Lancet 1997;349:1436-42.

2 Caplan LR. Treatment of acute stroke: still struggling. JAMA 2004;292:1883-5.

3 Burn J, Dennis M, Bamford J, et al. Long-term risk of recurrent stroke after a first-ever stroke. The Oxfordshire Community Stroke Project. Stroke 1994;25:333-7.

4 Kannel WB, Wolf PA, Verter J, et al. Epidemiologic assessment of the role of blood pressure in stroke. The Framingham study. JAMA 1970;214:301-10.

5 Kannel WB, McGee DL. Diabetes and cardiovascular disease. The Framingham study. JAMA 1979;241:2035-8.

6 Wolf PA, D'Agostino RB, Kannel WB, et al. Cigarette smoking as a risk factor for stroke. The Framingham Study. JAMA 1988;259:1025-9.

7 Hack W, Kaste M, Bogousslavsky J, et al. European stroke initiative recommendations for stroke management-update 2003. Cerebrovasc Dis 2003; 16:311-37.
8 Redfern J, McKevitt C, Dundas R, et al. Behavioral risk factor prevalence and lifestyle change after stroke: a prospective study. Stroke 2000;31:1877-81.

9 PROGRESS Collaborative Group. Randomised trial of a perindopril-based blood-pressure-lowering regimen among 6,105 individuals with previous stroke or transient ischaemic attack. Lancet 2001;358:1033-41.

10 Hankey GJ, Warlow CP. Treatment and secondary prevention of stroke: evidence, costs, and effects on individuals and populations. Lancet 1999;354:1457-63.

11 Girot M, Mackowiak-Cordoliani MA, Deplanque D, et al. Secondary prevention after ischemic stroke. Evolution over time in practice. I Neurol 2005;252: 14-20.

12 Kothari R, Sauerbeck L, Jauch E, et al. Patients' awareness of stroke signs, symptoms, and risk factors. Stroke 1997;28:1871-5.

13 Ferris A, Robertson RM, Fabunmi R, et al. American Heart Association and American Stroke Association national survey of stroke risk awareness among women. Circulation 2005;111:1321-6.

14 Croquelois A, Assal G, Annoni JM, et al. Diseases of the nervous system: patients' aetiological beliefs. J Neurol Neurosurg Psychiatry 2005;76:582-4.

\section{HISTORICAL NOTE}

\section{Queckenstedt's manoeuvre}

7 his paper describes the beginnings of the measurement of CSF pressure and its physiological fluctuations by Queckenstedt that culminated in his clinical test for spinal canal obstruction.

In 1891, Walter Essex Wynter, physician to the Middlesex Hospital, described the insertion of a Southey's tube to withdraw infected cerebrospinal fluid (CSF) to reduce CSF pressure in meningitis. One month earlier, Heinrich Irenaeus Quincke (1842-1922), who held Chairs in Berne and then Kiel, described lumbar puncture. ${ }^{1}$ The procedure was quickly established.

Hans Queckenstedt, while serving in the army in 1916, devised his test to detect spinal cord compression. He described:

\begin{abstract}
"The narrowed [spinal] channel impedes movement of fluid with an increase in pressure above the compression site... The increment in pressure above the obstruction can be demonstrated by compression of the neck..., which produces an increase in venous blood in the cranial cavity, with concomitant reduction in space for the cerebrospinal fluid... The increased fluid pressure immediately transmitted throughout the system normally can be demonstrated with a... manometer attached to a lumbar puncture needle. In lesions of the cord the manometric change is greatly retarded."
\end{abstract}

Its occasional use is still described, ${ }^{3}{ }^{4}$ although it has been mainly replaced by imaging, usually magnetic resonance imaging of the spinal canal. The lumbar puncture was performed with the patient in lateral decubitus position. Queckenstedt measured the opening pressure. Then, his assistant compressed both jugular veins, which led to a sharp rise in the pressure of the spinal fluid transmitted to the lumbar region within 10-12 seconds, succeeded by a fall when jugular pressure was released. If there was stenosis in the spinal canal, there was a reduced or absent response in the manometric pressure, recorded as a positive Queckenstedt's manoeuvre.

It is said 5 that the Guy's Hospital surgeon and anatomist John Hilton (1804-1878) "on the basis of investigation of a corpse" described the phenomenon earlier, in 1863. Simultaneous cerebral and spinal fluid pressure recordings are a later extension of the manoeuvre, used to show cerebrospinal dissociation in lesions at the foramen magnum. ${ }^{6}$

doi: 10.1136/jnnp.2005.083618

Hans Heinrich Georg Queckenstedt (1876-1918)

Born in Leipzig, son of an impoverished schoolmaster, Queckenstedt graduated from Leipzig University in 1900. A pupil of Emil Kraepelin (1856-1926), he trained with Ganser and obtained his doctorate in 1904, and then went to work with Martius in Rostock. His studies of iron metabolism in pernicious anaemia secured promotion to Privatdozent in 1913. He began to investigate the dynamics and constituents of CSF and noticed the fluctuations of CSF pressure with respiration. This led to his studies using the Valsalva manoeuvre and jugular compression, published in 1916, during his service in the First World War. He became chief of the Army Medical Services in Harburg near Hamburg. He also wrote about the periostitis of typhoid fever. Ironically, in the final days of conflict, two days before the armistice, he was thrown from a horse while on duty and killed by a passing munitions truck ${ }^{7}$ while still a young man.

\section{J M S Pearce \\ Department of Neurology, Hull Royal Infirmary, UK}

Correspondence to: J M S Pearce, 304 Beverley Road, Anlaby, East Yorks, HU10 7BG, UK; imsp@freenet.co.uk

There are no conflicting interests or financial support in this work. This paper has not been submitted to any other journal.

Competing interests: None declared.

\section{References}

1 Pearce JMS. History of lumbar puncture. In:Pearce JMS. Fragments of neurological history, 1st ed. London: Imperial College Press, 2003:201-6.

2 Queckenstedt HHG. Zur Diagnose der Rückenmarkskompression. Deutsche Zeitschrift für Nervenheilkunde, 1916;55: 325-333, Cited in:Talbott JH. A biographical history of medicine: excerpts and essays on the men and their work, New York:Grunne and Stratton, 1970:983.

3 Clough C, Pearce JMS. Lumbar puncture: Procedures in practice. Br Med J 1980;280:297-9.

4 Miyamoto $\mathbf{H}$, Sumi M, Kataoka O, et al. Traumatic spondylolisthesis of the lumbosacral spine with multiple fractures of the posterior elements. J Bone Joint Surg Br 2004;86:115-18.

5 Hilton J. On rest and pain: a course of lectures on the influence of mechanical and physiological rest in the treatment of accidents and surgical diseases, and the diagnostic value of pain, Delivered at the Royal College of Surgeons of England in 1860, 1861, and 1862. Jacobson W H A, eds. London: Bell and Daldy, 1863, Cited by Ole Daniel Enersen.http://www.whonamedit.com/ synd.cfm $/ 3302 . \mathrm{html}$.

6 Williams B. Simultaneous cerebral and spinal fluid pressure recordings. 2. Cerebrospinal dissociation with lesions at the foramen magnum. Acta Neurochirurgica 1981;59:123-42.

7 Anonymous. Hans Queckenstedt (1876-1918), neurophysiologist. JAMA 1968;203:883-4 